\title{
Ultrasonographic Evaluation of the Yolk Sac Diameter and Shape in the First Trimester of Pregnancy and Its Relation to Pregnancy Outcome
}

\author{
Hanan Atef Ahmed Ghali, Amr Abd Almohsen Alnemr, \\ Mohamed Abd Al moniem Ibrahem, Ayat Ahmed Hassan Abou Elkhair* \\ Department of Obstetrics and Gynecology, Faculty of Medicine, Zagazig University, Sharkia, Egypt \\ *Corresponding Author: Ayat Ahmed Hassan Abou Elkhair, Mobile: (+20)01029293980,
}

ABSTRACT

Email: Ayatabouelkhair@gmail.com

Background: Transvaginal sonography is used to assess the viability of first-trimester pregnancy. Significant data regarding normal and abnormal ultrasonographic measurements of the yolk sac (YS). The study aimed to know pregnancy outcome by assessing the role of ultrasonographic evaluation of yolk sac diameter and its shape in the first trimester.

Patients and Methods: This study was conducted at the Obstetrics and Gynecology Department, Zagazig University Hospitals on 72 pregnant women in their first trimester of pregnancy. All pregnant women in their first trimester of pregnancy referred by the Department of Obstetrics for transvaginal sonography. All pregnancies with an abnormal appearing yolk sac were re-evaluated by sonography after two weeks.

Results: The mean age was $26.9 \pm 3.9$ years. It was found that there was no significant relationship between maternal age and pregnancy outcome. Regarding the absence of the yolk sac. It was not visualized in three cases, and all of them aborted later. Total mean YSD \pm S.D was $3.7 \pm 1.8 \mathrm{~mm}$, seen in GA from 6-9th weeks and there was no significant difference between the studied groups as regard YSD. Regarding normal YSD with the abnormal outcome, three cases with a normal YSD and regular morphology aborted after the $8^{\text {th }}$ week of gestation. Regarding large-sized YSD, it was found in three cases; two cases ended in a missed miscarriage at 8th week with YSD 8.4 $\mathrm{mm}$ and $8.2 \mathrm{~mm}$ respectively. In contrast, the third one with YSD $6.8 \mathrm{~mm}$ finally continued beyond 20 weeks with no demonstrable fetal anomalies. Regarding small-sized YSD; it was found in one case which ended in missed abortion at 7th week. Regarding the shape of the YS, an echogenic YS was detected in one case.

Conclusion: The yolk sac diameter and shape as a sole parameter is a poor predictor for pregnancy outcome beyond 20 weeks and may be related to early pregnancy loss only. If any abnormality is observed, close follow up with ultrasonography is recommended for these pregnancies.

Keywords: Pregnancy outcome, Ultrasonographic evaluation, yolk sac, first trimester.

\section{INTRODUCTION}

Pregnancy is one of the most marvelous events which a woman experiences in her life and reality of the whole life, the first trimester is a vital time as the pregnancy gets established ${ }^{(\mathbf{1})}$.

It was concluded that ultrasonography (USG) plays an important role in differentiating normal from abnormal pregnancies and therefore in the prediction of its wellness accurately. It gives an accurate diagnosis in the majority of pregnant women in the first trimester and also defines a reliable differentiation between viable pregnancy and ongoing abnormal pregnancy ${ }^{(2)}$.

Transvaginal sonography is used to assess the viability of first-trimester pregnancy. The ultrasound cut- offs for defining miscarriage have been prospectively validated. Also, the timing of subsequent ultrasound scans in women with an intrauterine pregnancy of uncertain viability (IPUV) has been outlined ${ }^{(3)}$.

Abdallah et al. ${ }^{(4)}$ reported a significant data regarding normal and abnormal ultrasonographic measurements of the gestational sac (GS), yolk sac (YS), crown-rump length (CRL) in early gestations. These parameters have been studied for both purposes of predicting early pregnancy failure and establishing standardized parameters for each gestational age.

The secondary yolk sac (SYS) is the first extraembryonic structure which can be detected by transvaginal sonography (TVS) in the chorionic cavity and can be seen from the $5^{\text {th }}$ to the $12^{\text {th }}$ week of pregnancy and it can be detected in normal pregnancies, the primary yolk sac cannot be visualized on ultrasound ${ }^{(5)}$.

The yolk sac plays an important role during the period of organogenesis providing metabolic, immunological, endocrinal, nutritional, and hemopoietic functions, and its highest level of functional activity is reached between the $4^{\text {th }}$ to $7^{\text {th }}$ week of development ${ }^{(\boldsymbol{6})}$.

The study aimed to know pregnancy outcome by assessing the role of ultrasonographic evaluation of yolk sac diameter and its shape in the first trimester.

\section{PATIENTS AND METHODS}

A-Technical design:

- Setting: This study was conducted at the Obstetrics and Gynecology Department, Zagazig University Hospitals. 
- Sample size: the sample size is 72 pregnant women in their first trimester of pregnancy.

- Study design: A prospective cohort study.

- Duration of study: From September 2018 to September 2019

Inclusion criteria: All pregnant women in their first trimester of pregnancy at 6-11 weeks of pregnancy referred by the Department of Obstetrics for transvaginal sonography were recruited for the study

\section{Exclusion criteria:}

- Pregnant women with multifetal gestation.

- Vaginal bleeding.

- Pregnant women below 18 and above 35 years old.

- Structural anomalies of uterus and cervix.

- Chronic diseases as (SLE, hypertension, diabetes, and cardiac disease).

- Recurrent fetal loss.

- Pregnant patients refusing transvaginal sonography or who were unwilling for follow up.

\section{B- Study design:}

Type of study: A prospective cohort study.

Methods: All patients will be subjected to the following:

1. Informed consent: was taken from the antenatal women to share in the study and the study design was discussed.

\section{Complete history taking, particularly for:}

- Menstrual history

- Obstetric history

- Medical disorder that affects pregnancy

- Vaginal bleeding

\section{Transvaginal ultrasound (TVS):-}

All pregnant women in their first trimester of pregnancy referred by the Department of Obstetrics for transvaginal sonography were recruited for the study based on inclusion/exclusion criteria after informed consent using (SIEMENS ACUSON X 300 Medical Systems, Korea) ultrasound machine with the 2D endovaginal probe with frequency $7 \mathrm{MHz}$.

\section{Clinical Follow Up:}

All pregnancies with an abnormal appearing yolk sac were re-evaluated by sonography after two weeks. All selected cases were scheduled for nuchal translucency measurement between the $11^{\text {th }}$ and 14th week of gestation and a fetal anomaly scan was undertaken between the 18th and 22nd week of gestation.
C-Administrative design: Patients are counseled for different diagnostic options and verbal informed consent was obtained. The study was approved by the ethical committee of the hospital.

\section{Ethical consideration:}

- Approval was obtained from the Institutional Review Board (IRB) at Zagazig University Hospitals.

- Women were informed that the study results would be used only for research and the study procedures will be free from any harmful effects on them.

\section{Data analysis}

- The range of normal Yolk sac diameter was considered to be $2-5 \mathrm{~mm}$. A large yolk sac was defined as a yolk sac with a diameter $>5 \mathrm{~mm}$ and small with a diameter $<2 \mathrm{~mm}$.

- The patients were followed and considered as normal pregnancy outcome if the pregnancy continued beyond 20 weeks and abnormal outcome if they ended in abortion or demonstrable fetal anomalies.

\section{Statistical analysis}

Data were then imported into Statistical Package for the Social Sciences (SPSS version 20.0) (Statistical Package for the Social Sciences) software for analysis. According to the type of data qualitative represent as number and percentage, a quantitative continuous group represented by mean $\pm \mathrm{SD}$, the following tests were used to test differences for significance; difference and association of qualitative variable by Chi-square test $\left(\mathrm{X}^{2}\right)$. Differences between quantitative independent groups by t-test, ROC curves were done. P-value was set at $<0.05$ for significant results.

\section{RESULTS}

Table 1 shows that there is no significant correlation between age group and pregnancy outcome

Table 2 shows that there is no significant difference between Pregnancy outcome normal and abnormal yolk sac in the studied cases.

Table 3 shows that there is no significant difference between the studied groups regarding yolk sac diameters.

Table 4 shows that there is a significant difference between the studied groups regarding gestational sac diameters in the $8^{\text {th }}$ week while there is no statistically significant difference between the studied groups regarding gestational sac diameters in the $7^{\text {th }}$ or $6^{\text {th }}$ week. 
Table (1): Relation between age and pregnancy outcome

\begin{tabular}{|c|c|c|c|c|c|c|}
\hline Outcome: & Age group: & $\mathbf{2 0}$ & $\mathbf{2 1 - 3 0}$ & $\mathbf{> 3 0}$ & $\boldsymbol{\chi}^{\mathbf{2}}$ & P-value \\
\hline $\begin{array}{c}\text { Continued } \\
\text { beyond 20 } \\
\text { weeks (n=63) }\end{array}$ & No & $\mathbf{2}$ & 47 & 13 & & \\
\cline { 1 - 5 } $\begin{array}{c}\text { Aborted } \\
(\mathbf{n}=\mathbf{9})\end{array}$ & $\mathbf{\%}$ & 3.2 & 75.8 & 21.0 & \multirow{2}{*}{5.47} & \multirow{2}{*}{ NS } \\
\cline { 2 - 5 } & $\mathbf{\%}$ & 20.0 & 50.0 & 30.0 & & \\
\hline
\end{tabular}

P-value is considered significant if $<0.05$. NS (Non-significant)

Table (2): Pregnancy outcome of normal and abnormal yolk sac in the studied cases

\begin{tabular}{|c|c|c|c|c|c|c|c|}
\hline Outcome: & & $\begin{array}{l}\text { Nor } \\
\text { mal }\end{array}$ & Large & Absent & Echogenic & Small & $\begin{array}{c}\mathrm{P}- \\
\text { value }\end{array}$ \\
\hline \multirow{2}{*}{$\begin{array}{c}\text { Continued } \\
\text { beyond } 20 \\
\text { weeks }(n=63)\end{array}$} & No & 61 & 1 & Nil & 1 & Nil & \multirow{4}{*}{ NS } \\
\hline & $\%$ & 84.7 & 1.4 & Nil & 1.4 & Nil & \\
\hline \multirow{2}{*}{$\begin{array}{c}\text { Aborted } \\
(\mathbf{n}=9)\end{array}$} & No & 3 & 2 & 3 & Nil & 1 & \\
\hline & $\%$ & 4.2 & 2.7 & 4.2 & Nil & 1.4 & \\
\hline Total & & 64 & 3 & 3 & 1 & 1 & \\
\hline
\end{tabular}

Table (3): Yolk sac diameters in different gestational ages and its relation to pregnancy outcome

\begin{tabular}{|c|c|c|c|c|}
\hline $\begin{array}{l}\text { Gestational } \\
\text { age(weeks) }\end{array}$ & $6^{\text {th }}$ week & $7^{\text {th }}$ week & $8^{\text {th }}$ week & $\begin{array}{c}\text { P- } \\
\text { value }\end{array}$ \\
\hline & \multicolumn{3}{|c|}{ Mean \pm SD } & \multirow{5}{*}{ NS } \\
\hline 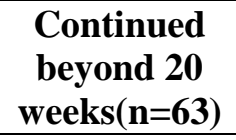 & $3.43 \pm 0.52 \mathrm{~mm}$ & $3.75 \pm 0.63 \mathrm{~mm}$ & $4.4 \pm 0.96 \mathrm{~mm}$ & \\
\hline \multirow[t]{3}{*}{$\begin{array}{c}\text { Aborted } \\
(\mathbf{n}=9)\end{array}$} & $2.74 \pm 0.91 \mathrm{~mm}$ & $4.72 \pm 3.2 \mathrm{~mm}$ & $5.4 \pm 3.9 \mathrm{~mm}$ & \\
\hline & T-test & \multicolumn{2}{|c|}{ MW } & \\
\hline & 1.69 & 36.5 & 10.0 & \\
\hline
\end{tabular}

Table (4): Gestational sac diameters in different gestational ages and its relation to pregnancy outcome

\begin{tabular}{|c|c|c|c|}
\hline Gestational age(weeks) & $\mathbf{6}^{\text {th }}$ week & $\mathbf{7}^{\text {th }}$ week & $\mathbf{8}^{\text {th }}$ week \\
\hline & \multicolumn{3}{|c|}{ Mean \pm SD } \\
\hline $\begin{array}{c}\text { Continued beyond 20 } \\
\text { weeks(n=63) }\end{array}$ & $19.2 \pm 5.1 \mathrm{~mm}$ & $25.6 \pm 8.1 \mathrm{~mm}$ & $29.2 \pm 2.7 \mathrm{~mm}$ \\
\hline Aborted (n=9) & $25 \pm 8.2 \mathrm{~mm}$ & $22.3 \pm 7.9 \mathrm{~mm}$ & $35.5 \pm 0.7 \mathrm{~mm}$ \\
\hline T test & 1.7 & 0.822 & 3.11 \\
\hline P value & $\mathrm{NS}$ & $\mathrm{NS}$ & $\mathbf{0 . 0 1 1}(\mathbf{S})$ \\
\hline
\end{tabular}




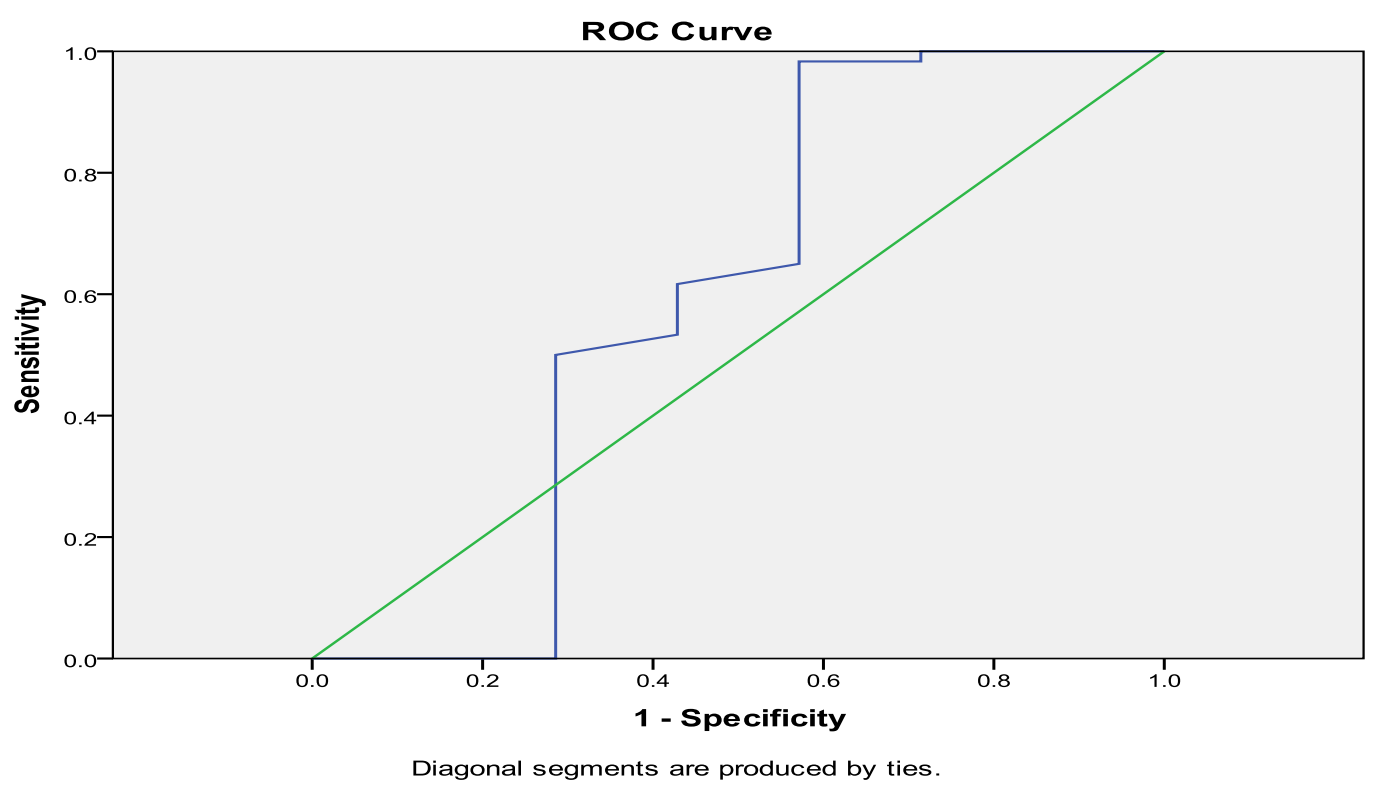

Figure (1): ROC Curve for yolk sac as a predictor of pregnancy outcome

\begin{tabular}{|c|c|c|c|c|c|c|}
\hline Area & P & Sensitivity & Specificity & Best cut off & \multicolumn{2}{|c|}{$\begin{array}{l}\text { 95\% Confidence } \\
\text { Interval }\end{array}$} \\
\cline { 4 - 7 } & & & & & $\begin{array}{l}\text { Lower } \\
\text { Bound }\end{array}$ & $\begin{array}{c}\text { Upper } \\
\text { Bound }\end{array}$ \\
\hline 0.616 & 0.248 & $96.8 \%$ & $50.0 \%$ & 0.265 & 0.353 & 0.876 \\
\hline
\end{tabular}

\section{DISCUSSION}

Regarding the maternal age of the studied group. The mean age was $26.9 \pm 3.9$ years and ranged from (20-33). It was found that there was no significant correlation between maternal age and pregnancy outcome. These findings agreed with studies by Abo Elwan et al. ${ }^{(7)}$.

Regarding the absence of the yolk sac. It was not visualized in three cases, and all of them aborted later Shetty et al. ${ }^{(8)}$ agreed with these findings.

Josel and Abdul Latheef ${ }^{(9)}$ also reported that the yolk sac visualization is for a normal pregnancy outcome.

Regarding the size of the yolk sac; the total mean YSD \pm S.D was $3.7 \pm 1.8 \mathrm{~mm}$, seen in GA from $6-9^{\text {th }}$ weeks and there was no significant difference between the studied groups as regard YSD. These findings agreed with results by Farag et al. ${ }^{(10)}$ who reported that an abnormally sized YSD was the weakest predictor of spontaneous abortion in the presence of normal GSD, CRL, and FHR measurement, and demonstrated that normal YSD did not reduce the risk of abortion. Also in agreement with a study by Suguna and Sukanya
${ }^{(11)}$ who reported that yolk sac diameter alone is a weaker indicator of pregnancy outcome.

Regarding normal YSD with the abnormal outcome, three cases with a normal YSD and regular morphology aborted after the $8^{\text {th }}$ week of gestation.

Salah et al. ${ }^{(12)}$ who conducted a prospective cross-sectional study of 400 cases reported 25 cases with normal YS size and shape had failed pregnancy.

Burton and Jauniaux ${ }^{(\mathbf{1 3 )}}$ reported an abnormal outcome with normal YS size and shape. These findings support that not usually YSD of normal range will eventually have a good outcome. Changes in YS morphology may reflect an abnormal embryonic development or death, rather than being a primary cause of pregnancy loss. Another explanation, Between 8th and 10th weeks of gestation; the disappearance of arterial signals in the yolk sac circulation and simultaneously an increase in the umbilicoplacental blood flow indicates that the transition from the yolk sac to the placenta occurs as an important source of blood supply to the embryo and may be a defect in the switch to umbilicoplacental blood flow occur at this time. This may be considered an etiology for 
miscarriage, and further studies are required at this particular gestational age.

Regarding large-sized YSD, it was found in three cases; Two cases ended in a missed miscarriage at $8^{\text {th }}$ week with YSD $8.4 \mathrm{~mm}$ and 8.2 $\mathrm{mm}$ respectively. In contrast, the third one with YSD $6.8 \mathrm{~mm}$ finally continued beyond 20 weeks with no demonstrable fetal anomalies.

Srivastava et al. ${ }^{(14)}$ detected large YSD with the abnormal outcome.

Regarding small-sized YSD; it was found in one case which ended in missed abortion at $7^{\text {th }}$ week.

Adija et al. (15) reported in their studies abnormally sized small YSD which finally had an abnormal outcome. No study in the literature reported a small YSD with a normal outcome. Abnormally small YSD is associated usually with adverse pregnancy outcomes.

Regarding the shape of the YS, an echogenic YS was detected in one case, it was seen at $7^{\text {th }}$ week of gestation with a diameter of $3.66 \mathrm{~mm}$ when first seen it was completed with the anechoic center and it turned clear again when seen after two weeks and surprisingly with a normal outcome at last. These findings agreed with the results of Tan et al. ${ }^{(6)}$ who demonstrated that irregular or echogenic YS appearance was unrelated to any increased risk of spontaneous miscarriage.

Using ROC curve analysis, the predictive value of the combination of YSD with GA (area under the ROC curve: 0.616) for pregnancy outcome with Sensitivity of $96.8 \%$ and specificity of $50.0 \%$ in comparison to a study by Abdellatif $e t$ al. (16) reported $75 \%$ sensitivity and $63.5 \%$ specificity and concluded that Yolk sac diameter only was a weaker predictor of abnormal outcome.

\section{CONCLUSION}

It was concluded from this study that the yolk sac diameter and shape as a sole parameter is a poor predictor for pregnancy outcome beyond 20 weeks and may be related to early pregnancy loss only. If any abnormality is observed, close follow up with ultrasonography is recommended for these pregnancies.

\section{REFERENCES}

1. Srivastava G, Nagwani M, Tewari V et al. (2018): The Correlation of Shape of Yolk Sac with Spontaneous Abortion- An Ultrasonographic Study. EJMR., 5(2): 128-133

2. Kumari S, Roychowdhury J, Biswas S (2016): Prediction of early pregnancy failure by use of first- trimester ultrasound screening. Int J Reprod Contracept Obstet Gynecol., 5:2135-40.

3. Kaur A, Kaur A (2011): Transvaginal ultrasonography in the first-trimester of pregnancy and its comparison with transabdominal ultrasonography. J Pharm Bioallied Sci., 3(3):329-38.

4. Abdallah Y, Daemen A, Guha $\mathrm{S}$ et al. (2011): Gestational sac and embryonic growth are not useful as criteria to define miscarriage: a multicenter observational study. Ultrasound Obstet Gynecol., 38: 503-509.

5. Tan S, Pektaş M, Arselan H (2012): Sonographic Evaluation of the Yolk Sac. J Ultrasound Med., 31:8795.

6. Tan S, Tangal N, Pektas M et al. (2014): Abnormal sonographic appearances of the yolk sac: which can be associated with adverse? perinatal outcome? Med Ultrason., 16:15-20.

7. Abo Elwan H, Lebeda I, Elfawal F et al. (2019): Prognostic Factors of Ultrasonography of Yolk Sac Size and Embryonic Heart Rate in First Trimester Pregnancy Outcome. Zagazig University Medical Journal, ZUMJ., 25(6);801-808.

8. Shetty A, Hegde D, Shetty B et al. (2015): Yolk Sac Abnormalities -Is it a Reliable Indicator of Abortions? A Prospective Study in the Population Residing in Rural Setup of Mangaluru, Karnataka, India. J Pharm Biomed Sci., 05(05): 380-384.

9. Josel L, Abdul Latheef N (2015): Sonographic evaluation of yolk sac. International Journal of Scientific \& Engineering Research, 6 (5): 11-15.

10. Farag AM, Ibrahim A, Abdel Salam S (2018): Ultrasonography and Pregnancy Outcome in Threatened Abortion: A Prospective Observational Study. Gynecol Obstet (Sunnyvale), 8: 481-5.

11. Suguna B, Sukanya K (2019): Yolk sac size \& shape as predictors of first-trimester pregnancy outcome: A prospective observational study. Journal Gynecol Obstet Hum Reprod., 48:159-164.

12. Salah M, Osama A, Mostafa S et al. (2016): Gestational sac size, yolk sac size, and embryonic cardiac activity as prognostic factors of first-trimester Pregnancy Outcome. N Y Sci J., 9(12):70-74.

13. Burton G, Jauniaux E (2018) Development of the Human Placenta and Fetal Heart: Synergic or Independent? Frontiers Physiol., 9:373-6.

14. Srivastava G, Mumal N, Navbir $P$ et al. (2016): Size of yolk sac by ultrasonography and its correlation with pregnancy outcome. International Journal of Anatomy and Research, 4(1):2052-57.

15. Adija P, Selvi C, Rai L et al. (2015): Evaluation of yolk sac diameter and embryonic heart rate as prognostic factors of gestational outcome in early singleton pregnancies. Scholars Journal of Applied Medical Sciences (SJAMS), 3(2A): 543-550.

16. Abd Ellatif E, Ahmad A, Halawa M (2018): Yolk Sac Size and Shape, Gestational Sac Diameter, and Embryonic Heart Rate as Prognostic Factors for First Trimesteric Outcome. The Egyptian Journal of Hospital Medicine, 73(9) 7418-7428. 